\title{
Testing Liquid Distribution in a Vane-Type Propellant Tank under Conditions of Microgravity Using a Drop Tower Test
}

\author{
Jintao Liu $\mathbb{D}^{1}{ }^{1}$ Yong Li, ${ }^{1}$ Wen $\mathrm{Li}^{1}{ }^{1} \mathrm{Hua} \mathrm{Zhai}^{2}$ and Lei Chen ${ }^{1}$ \\ ${ }^{1}$ Beijing Engineering Research Centre of Efficient and Green Aerospace Propulsion Technology, Beijing Institute of \\ Control Engineering, Beijing 100094, China \\ ${ }^{2}$ Beijing Institute of Tracking and Communication Technology, Beijing 100094, China
}

Correspondence should be addressed to Jintao Liu; liujt@tsinghua-tj.org

Received 7 August 2019; Revised 26 July 2020; Accepted 19 October 2020; Published 18 November 2020

Academic Editor: Jeremy Straub

Copyright ( 92020 Jintao Liu et al. This is an open access article distributed under the Creative Commons Attribution License, which permits unrestricted use, distribution, and reproduction in any medium, provided the original work is properly cited.

Propellant management devices (PMDs) are a key component used to manage liquid propellant in a propellant tank under zero gravity conditions. A microgravity drop tower test system was established to investigate the performance of a PMD. A single module was used for the experiments, and the microgravity level was less than $3 \times 10^{-3} \mathrm{~g}$. Anhydrous ethanol was used as the simulate liquid. Different volume fractions of liquid were used to study the influence of the PMD on performance management. Experiments were conducted with the position of the container oriented in different directions. Changes in the gas-liquid interface were studied during the test. This kind of vane transports liquid through the rectangular area between the vane and the wall. The velocity flows along the vane of different liquid volume fractions in the tank were different at the beginning $(t<0.8 \mathrm{~s})$ compared with the end of the test. The liquid relocation time was less than $0.8 \mathrm{~s}$ while the liquid volume fraction was larger than $25 \%$. The liquid relocation time was prolonged when the liquid volume fraction was less than $25 \%$. The liquid climbing height along the vane under microgravity increased as the volume fraction of liquid reduced. The climbing velocity of the liquid is half reduction when the liquid volume fraction is small. The time for the liquid transferred from the top of the tank to the liquid outlet can be obtained by climbing velocity. It shows that the maneuverability of the satellite decreases at the end of its life. The above results are applicable to all propellant tank with vertical vanes. These results provide a favorable reference for further optimized design of vertical vane-type propellant tanks.

\section{Introduction}

For liquid propulsion in a satellite, a propellant tank is used to store the propellant. The tank is complex that requires managing the liquid propellant under zero gravity to ensure that liquid, rather than gas, is expelled from the tank. The value and the direction of the gravity in space will affect the liquid separation in a tank [1]. To provide a gas-free propellant for thrusters of the propellant system in a satellite, the propellant management device (PMD) is used to manage the liquid and gas in a tank. PMD is also the key component for a tank during the orbital refueling process [2]. PMD must be designed to ensure that the tank outlet is sufficiently covered with liquid, and that it can transport liquid from anywhere in the tank to the outlet [3]. A vane-type tank is a new generation surface tension propellant tank, which has no screen inside it. The PMD of a vane-type tank is composed of a vane, a refillable reservoir, and other components [4]. The liquid inside the vane type tank is driven by the capillary force to the outlet of the tank.

Compared to screen channel liquid acquisition devices (LAD), vanes are open acquisition PMDs. Two types of vanes are used for the design of a vane-type propellant tank. One type of vanes is parallel to the tank wall, and it transports liquid through the space between the vane and the tank wall. The flow rate of the liquid depends on the width of the vane and the distance between the vane and the tank wall. The second type of vane is perpendicular to the tank wall, and it transports liquid through the rectangular area between the vane and the wall $[5,6]$. Vanes are particularly beneficial in satellite systems requiring periodic station-keeping maneuvers because satellites only require occasional access to the 


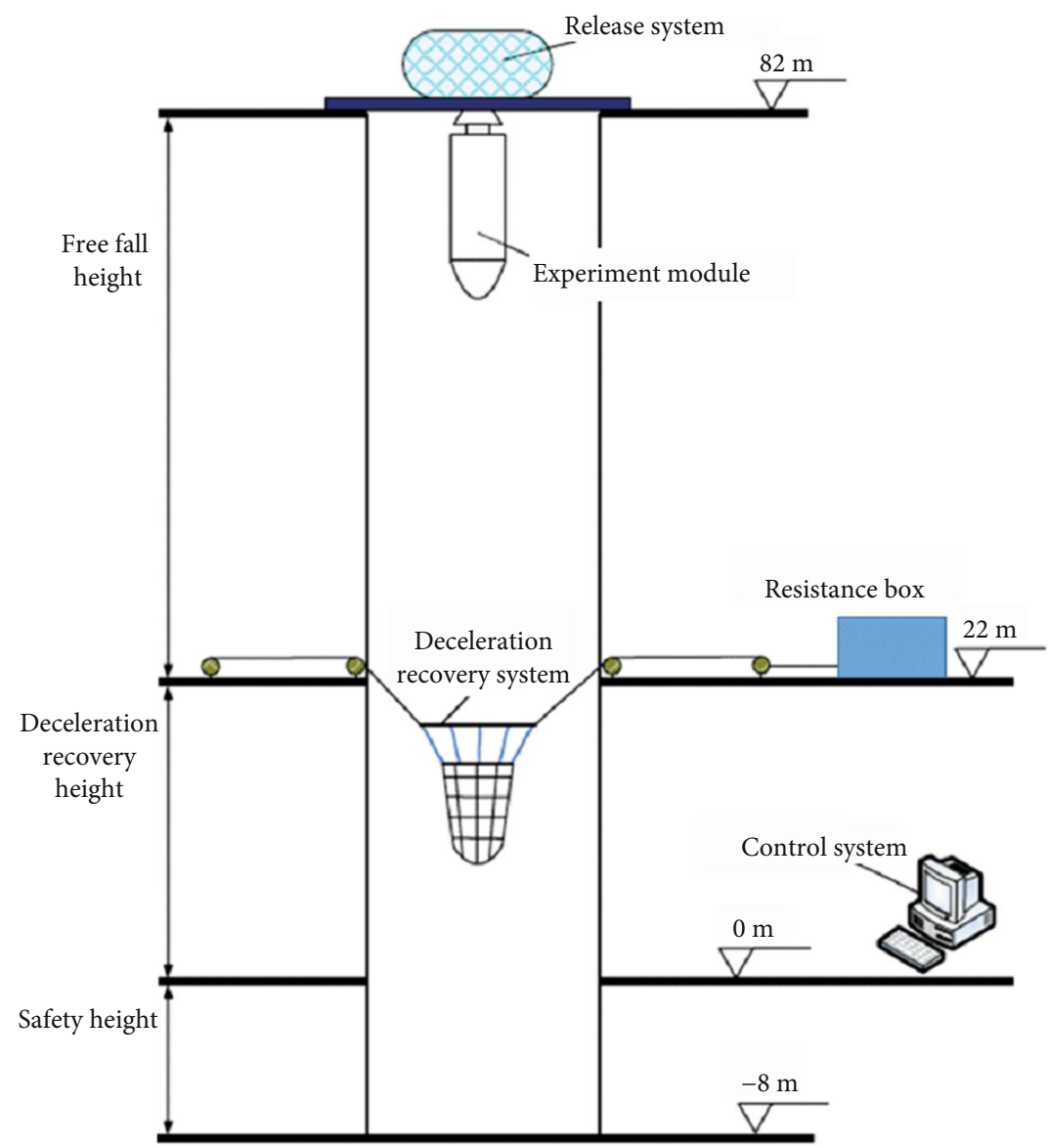

Figure 1: Drop tower test system.

propellant over the course of a long-duration mission [7]. A lightweight vane is also ideal to reduce the weight of the propellant tank. Vanes are the key component of a propellant tank [8]. A vane should be designed according to the value of gravity and the flow requirement for the propellant system $[9,10]$. When a new vane type tank is invented, the performance of the vane must be evaluated by the numerical or experimental investigation [11].

Because of the high cost, only three experiments were conducted in space with vane-type PMDs [12]. The first experiment was performed in the Fluid Acquisition Resupply Experiment-II (FARE-II) project to test the performance of a vane using a simulant fluid on-board the shuttle mission STS-57 [13]. The maximum achievable expulsion efficiencies under adverse acceleration levels were tested [14]. The second experiment was performed in the Vented Tank Resupply Experiment (VTRE) project [15]. Twelve outer and twelve inner vanes were mounted inside a small-scale plexiglass tank so that the liquid distribution in the tank can be clearly observed [16]. The third experiment was performed in an on-orbit filling project. A 4 liter tank with a vane-type PMD was sent into space using the rocket CZ-7 [17]. In orbit experiments, the liquid distribution in the tank was stable. It could only obtain the final gas-liquid distribution, and the performance of the vane was hard to evaluate in the orbit experiments.
One approach to evaluate the performance of a vane-type PMD is the drop tower test. Rui et al. [18] used a sphere scale vane tank to study the liquid-gas interface behaviors with different acceleration vectors and different filling independently. A series of stable equilibrium interface and relocation time was obtained. Bolleddula et al. [19] investigated the capillary flow phenomena using drop towers and concluded that compound capillary flows occurred spontaneously and simultaneously over local and global length scales. Li et al. [20] studied the capillary flow in an asymmetric interior corner in a vane-type surface tension tank. Zhuang et al. [21] conducted an experiment on the fluid storage characteristic of a refillable reservoir in microgravity. Kang et al. [22] and Liu et al. [23] investigated the fluid-gas interface in a vane-type surface tension tank by the drop tower test.

The relocation time for liquid in a tank from an instable state to a stable state is very important for the maneuverability of a satellite, and it can provide some control data for the attitude angle of a satellite. A new propellant tank should be tested to prove whether it can be used in space with the gravity level to provide gas-free propellant for thrusters. The drop tower test can also prove whether the tank can be refueled in space. In this study, a microgravity drop tower test system was established. Different liquid volume fractions were used to study the influence of the PMD on the liquid transport 


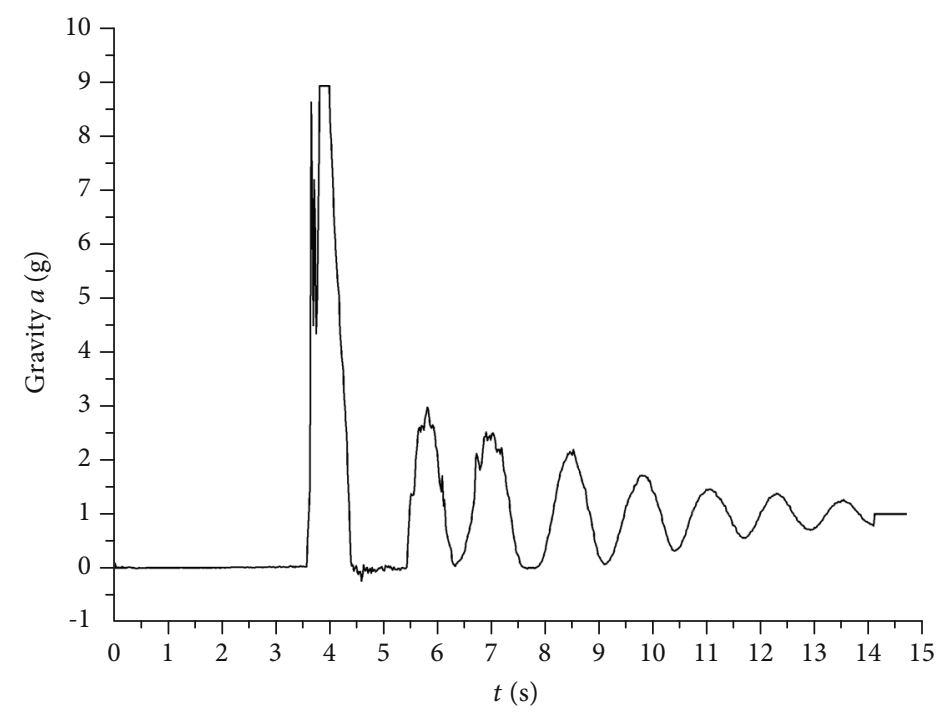

Figure 2: Gravity value during the drop tower test.

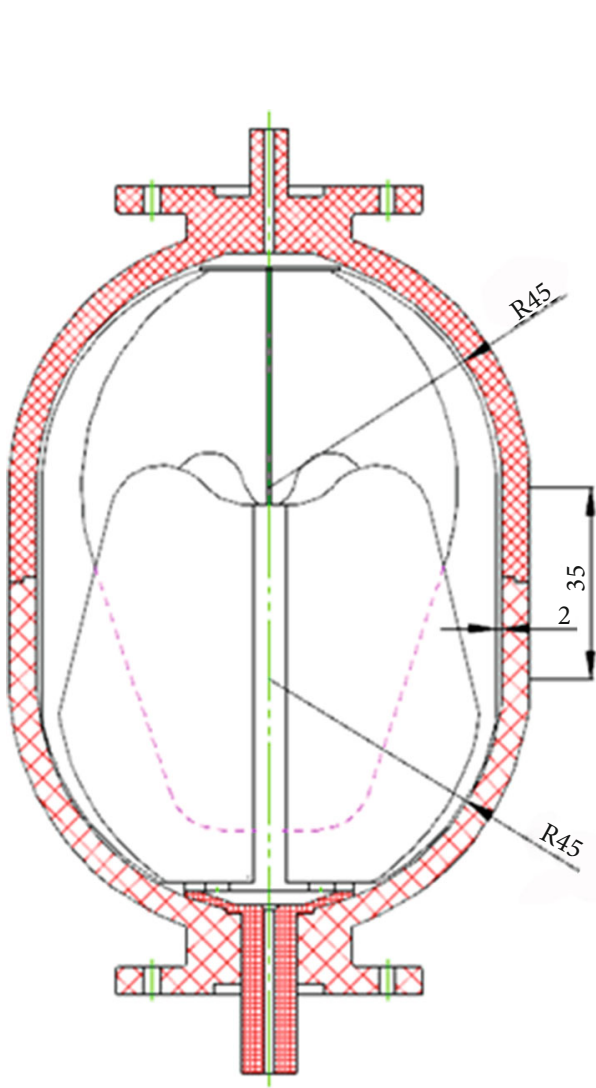

(a)

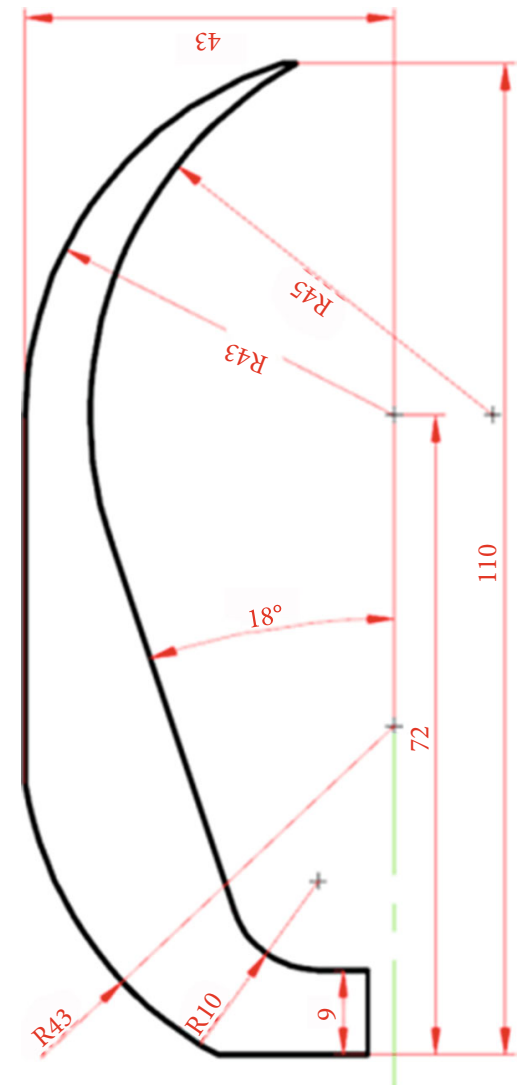

(b) Large vane

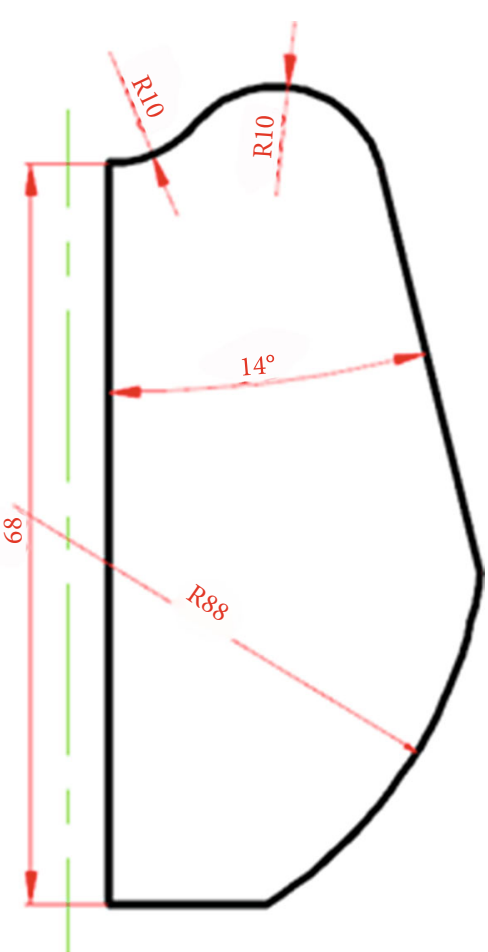

(c) Small vane

FIGURE 3: Vane-type propellant tank model.

performance. Several experiments were also performed with different directions of gravity. From the result of the drop tower test, the gas-liquid distribution in the tank during the whole life of the satellite decreases can be obtained. Another, the relocation time is also the time for the satellite to recover its attitude stability. From the drop tower test, the time for the liquid transferred from the top of the tank to the liquid outlet can be obtained. These results provide a favorable reference for the attitude control of a satellite.

\section{Drop Tower System}

Microgravity drop tower tests can be set up in a low microgravity environment within short time intervals. 


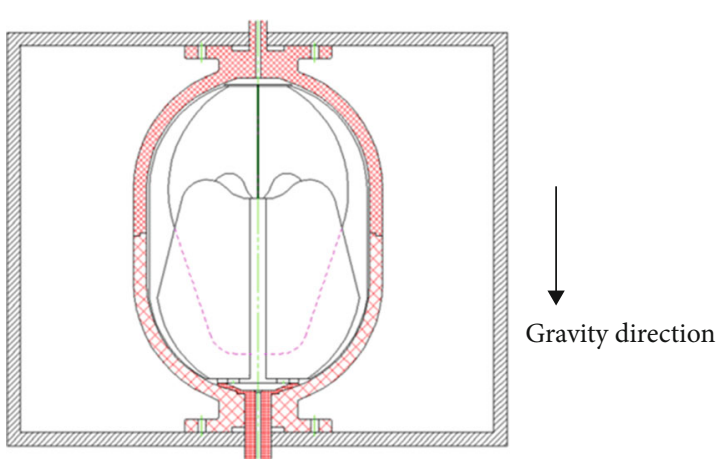

(a) Vertical direction

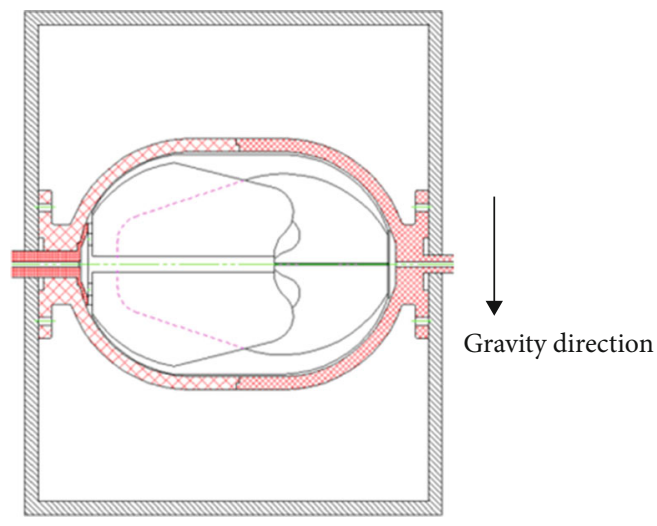

(b) Lateral direction

Figure 4: Different directions for the test.

Experiments on the vanes and refillable reservoir were carried out in microgravity conditions at the drop tower of National Microgravity Laboratory (NML) [8]. The NML free falling tower can maintain a microgravity condition in $3.5 \mathrm{~s}$. The drop tower test system, as observed in Figure 1, is composed of an experiment module, deceleration recovery system, release system, control system, and measurement system. The experiment module is the key component of the system, and it can provide a microgravity environment during the fall drop process. The experiment module is divided into two types, a double module and a single module. For the double module, the space between the internal module and outer module is vacuumized such that there is no resistance from the atmosphere. The internal module also free falls in the outer module. There is no resistance to the internal module during the fall process. The double module can provide microgravity between $10^{-4} \mathrm{~g}$ and $10^{-5} \mathrm{~g}$. $g$ is the acceleration on the Earth's surface. For the single module, the microgravity level is between $10^{-2} \mathrm{~g}$ and $10^{-3} \mathrm{~g}$.

The experimental module is set up on the ground and lifted to the top of the tower by a crane. The module is fixed on the release system by an electromagnetic device. At the beginning of the test, the release system is powered off and the electromagnetic force disappears and the experimental module free falls in the tower. The free fall height is $60 \mathrm{~m}$. The deceleration recovery system consists of a highstrength fiber net. The fiber net can avoid the damage of the test equipment caused by the violent impact on the experimental module. The resistance box can provide appropriate resistance force for the fiber net. The whole test is controlled by a control system.

The single or double module can be used separately for the requirements of an experimental microgravity level. Accordingly, single module is used for experiment of vanes and refillable reservoir. The gravity value during the drop tower test is observed in Figure 2. The microgravity level is smaller than $3 \times 10^{-3} \mathrm{~g}$. Gravity gradually increases during the fall process. The force caused by gravity is far less than the force caused by the surface tension. The influence of the gravity change on the flow can be ignored.

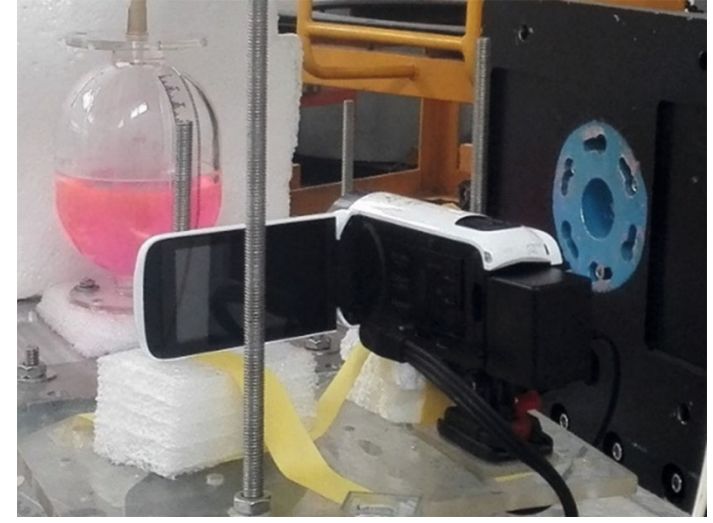

FIGURE 5: Camera for the measurement system.

\section{Test Model}

A new vane-type propellant tank was chosen for our study, which is shown in Figure 3. Vanes and refillable reservoir are the main components of the PMD. The volume of the tank is 2 liters. The tank has 4 large vanes and 4 small vanes. The diameter of the tank is $90 \mathrm{~mm}$. The selection of the tank size is based on the microgravity environment duration of the drop tower test. The size should make sure that the liquid relocation will be finished in a limited time.

The vane and tank casing are made of Plexiglas. The vanes are fixed on the Plexiglas casing and perpendicular to the container wall with a distance of $2 \mathrm{~mm}$. Microgravity drop tower tests were carried out for different liquid volume fractions. The effects of the volume fraction on liquid transfer velocity were studied. For the drop tower test, the resistance of the experiment module caused by air increases as the drop velocity increases.

The vane-type tank is fixed on the fixture as illustrated in Figure 4. Experiments with different gravity directions can be performed by this fixture. The location of the gas-liquid interface at the beginning is observed in the picture. A high-speed camera was used during the drop tower test. The changes in the climbing height of the gas-liquid interface and velocities can be derived from the pictures. The 


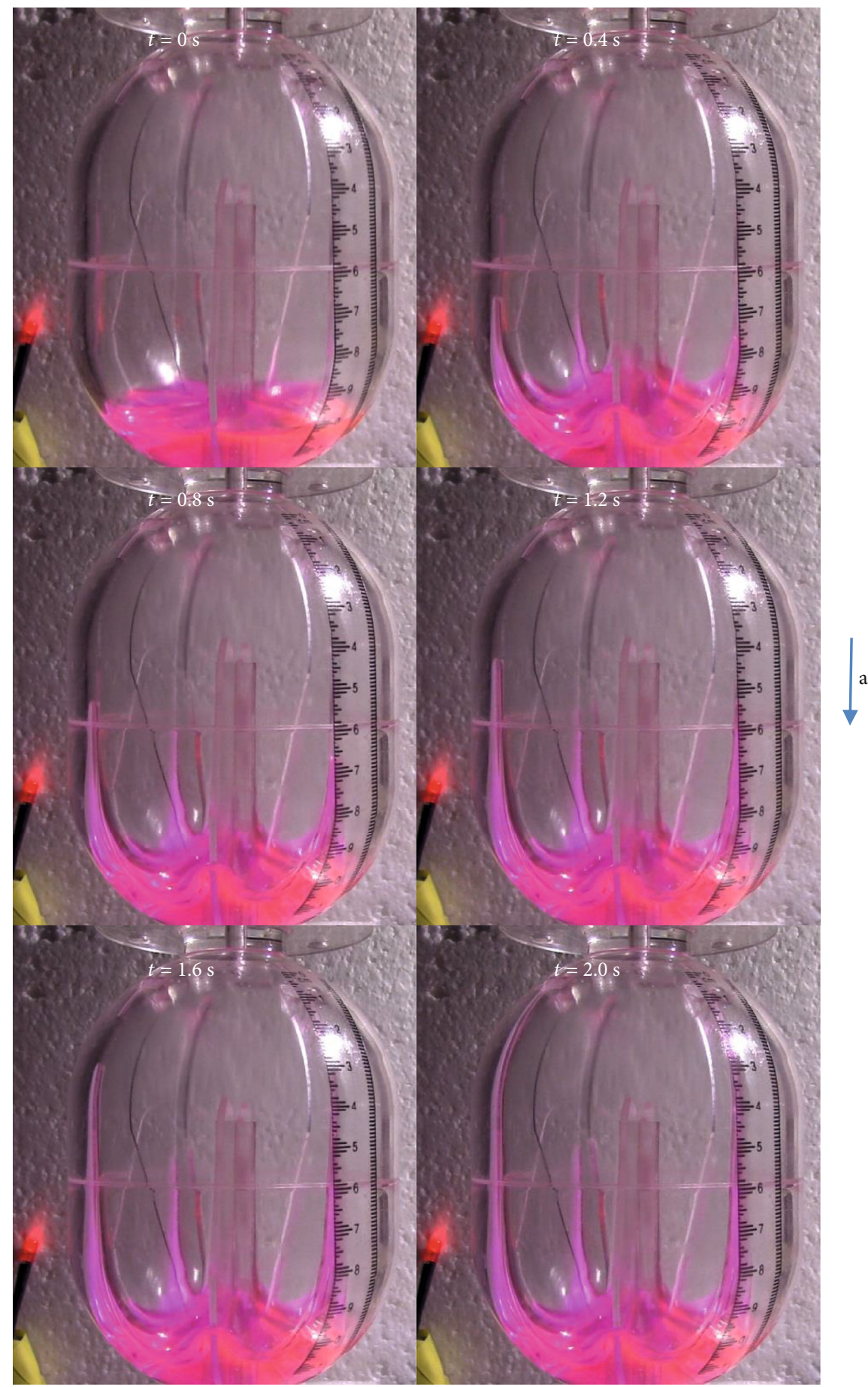

FIGURE 6: Liquid volume fraction is $5 \%$

relocation time, which is the time from the initial state of the liquid to the end of the flow of the liquid, can also be obtained.

The contact angle can be tested by the following equation:

$$
\cos \theta=\frac{\sigma_{23}-\sigma_{13}}{\sigma_{12}}
$$

where $\sigma_{12}$ is the surface tension coefficient between gas and liquid, $\sigma_{13}$ is the surface tension coefficient between gas and solid wall, and $\sigma_{23}$ is the surface tension coefficient between solid wall and liquid.

The contact angle between anhydrous ethanol and Plexiglas is $1^{\circ}$ when the temperature is $22^{\circ} \mathrm{C}$. The kinematic viscosity coefficient of anhydrous ethanol is $10.556 \times 10^{-4}$ Pa•s. The density of the anhydrous ethanol is $789 \mathrm{~kg} / \mathrm{m}^{3}$. The surface tension coefficient of anhydrous ethanol is $21.3 \mathrm{dyn} / \mathrm{cm}$.

The camera used for the measurement system is shown in Figure 5. The high-speed camera is set up in the experiment 


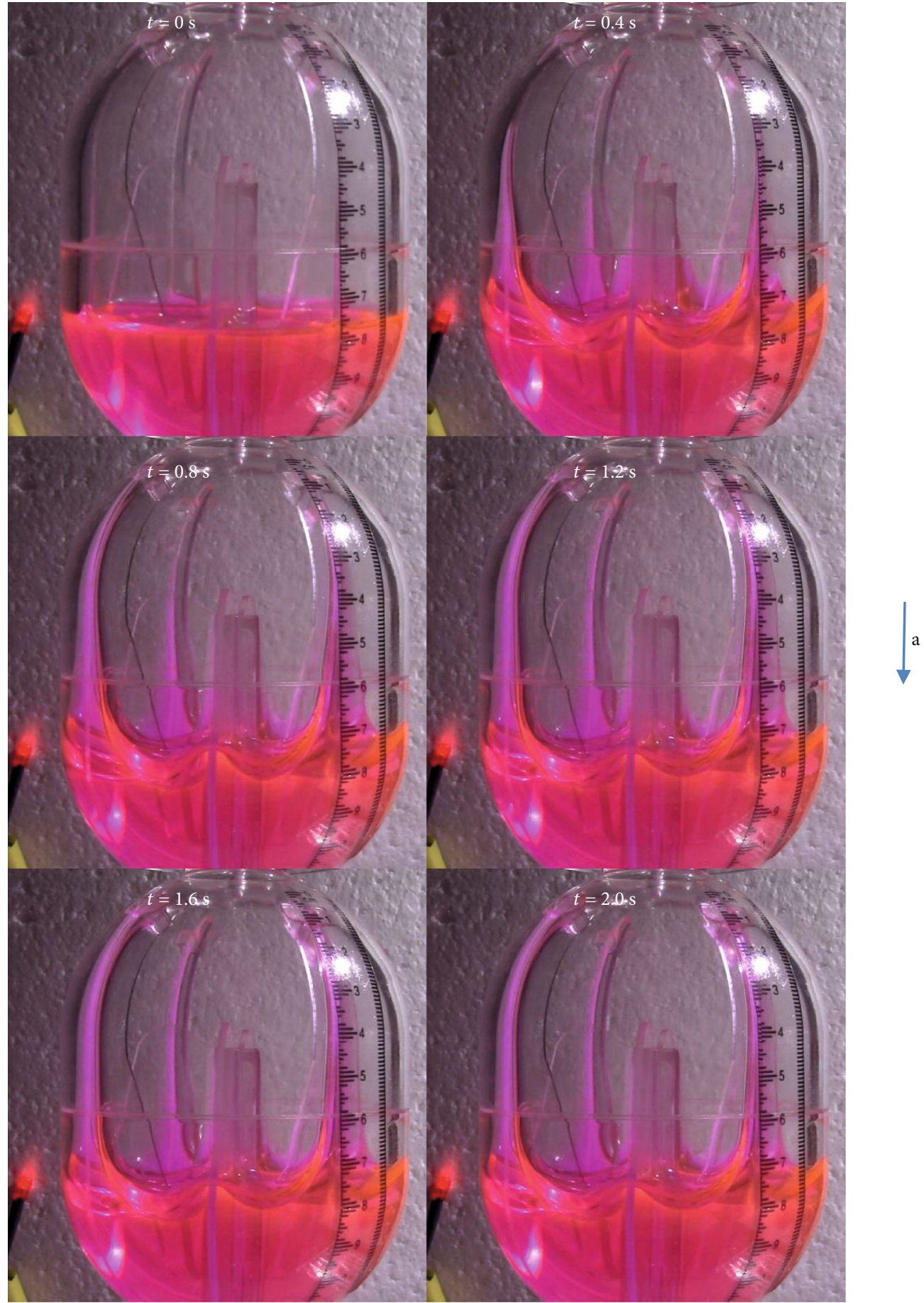

Figure 7: Liquid volume fraction is $25 \%$

module. The camera can film the whole process with $240 \mathrm{fps}$. A ruler is pasted along the curved surface of the tank. The unit of the ruler is millimeter. The location of the gas-liquid interface at the beginning is observed in the picture. A high-speed camera was used during the drop tower test. The change in the climbing height of the gas-liquid interface and velocities can be derived from pictures. From the ruler scale, the distance that the liquid-gas surface has moved can be obtained.
The top point of the gas-liquid interface in the hemispherical part is on a circle across the axial of the tank. Before calculating the distance, the center of the circle which is also the center of the sphere must be located from the picture. The top point of the gas-liquid surface and the center point of the circle should be aligned. The crossover point of the line with the ruler can be obtained. The distance $L_{\mathrm{o}}$ on the ruler can be measured. The external diameter of the tank is $R_{\mathrm{o}}$, and the internal diameter is $R_{\mathrm{i}}$. Further, the climbing height $h$ for 


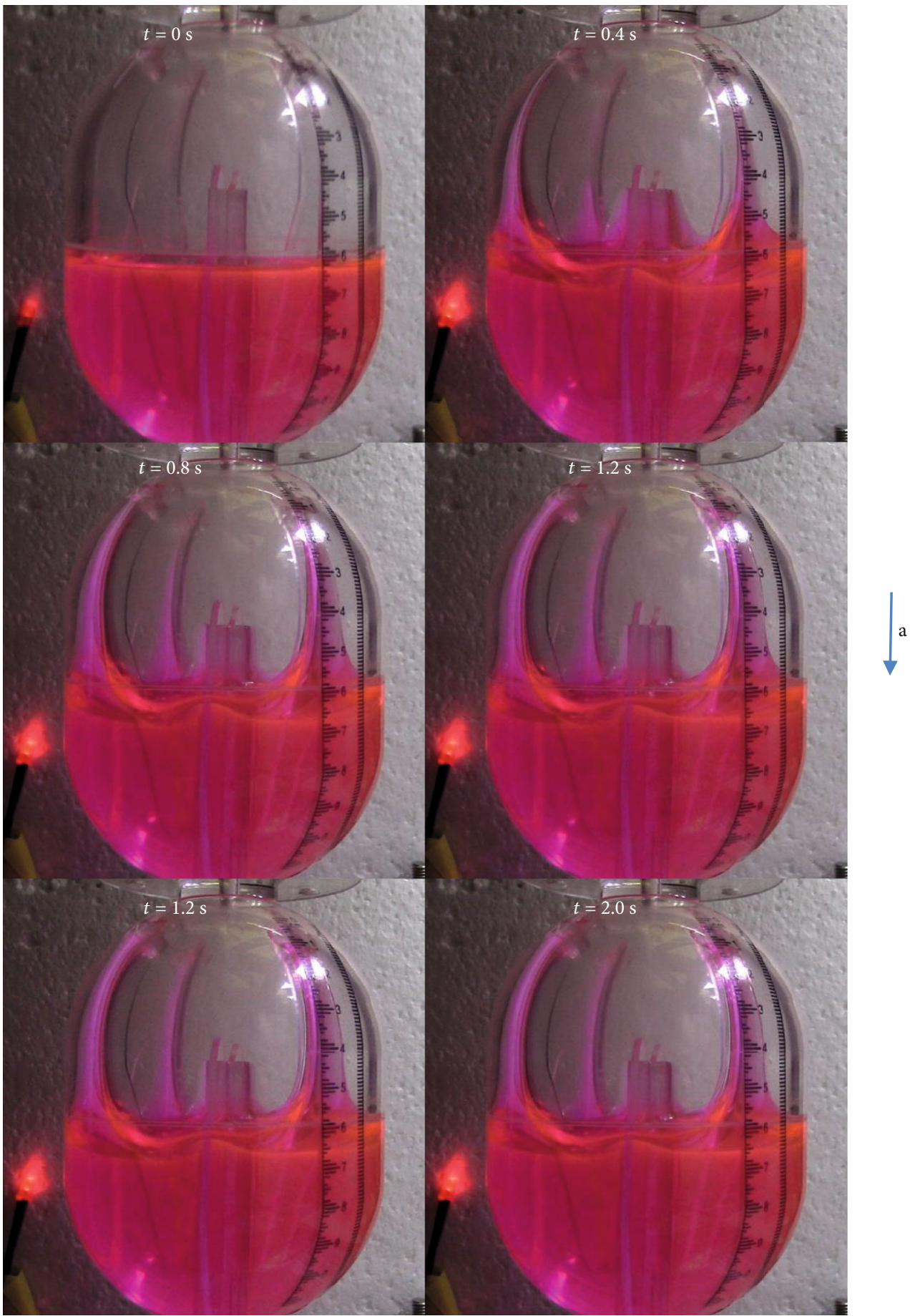

FIgURE 8: Liquid volume fraction is $40 \%$

the liquid in the hemispherical part can be calculated by the equation $h=L_{\mathrm{o}} \times R_{\mathrm{i}} / R_{\mathrm{o}}$. In the cylinder part, the distance can be calculated directly using the ruler scale.

\section{Experimental Result}

4.1. Drop Tower Test in the Vertical Direction. Five different liquid volume fractions are chosen for the drop tower test in a vertical direction. The chosen volume fractions are $5 \%$, $25 \%, 40 \%, 60 \%$, and $75 \%$. Experimental results are shown in Figures 6-10. At the beginning, anhydrous ethanol forms a curved concave gas-liquid interface due to the surface tension and static pressure balance formed by solid, liquid, and gas in the gap. When the experimental model begins to drop, the gravity environment of the tank changes from $1 \mathrm{~g}$ to $10^{-}$ ${ }^{3} \mathrm{~g}$. At this point, the surface tension begins to play an important role. The initial balance of the liquid inside the tank is broken, and the surface is stretched along the vane inside the tank. Under the effect of the surface tension, the liquid begins to flow. The liquid in the tank flows from the place 


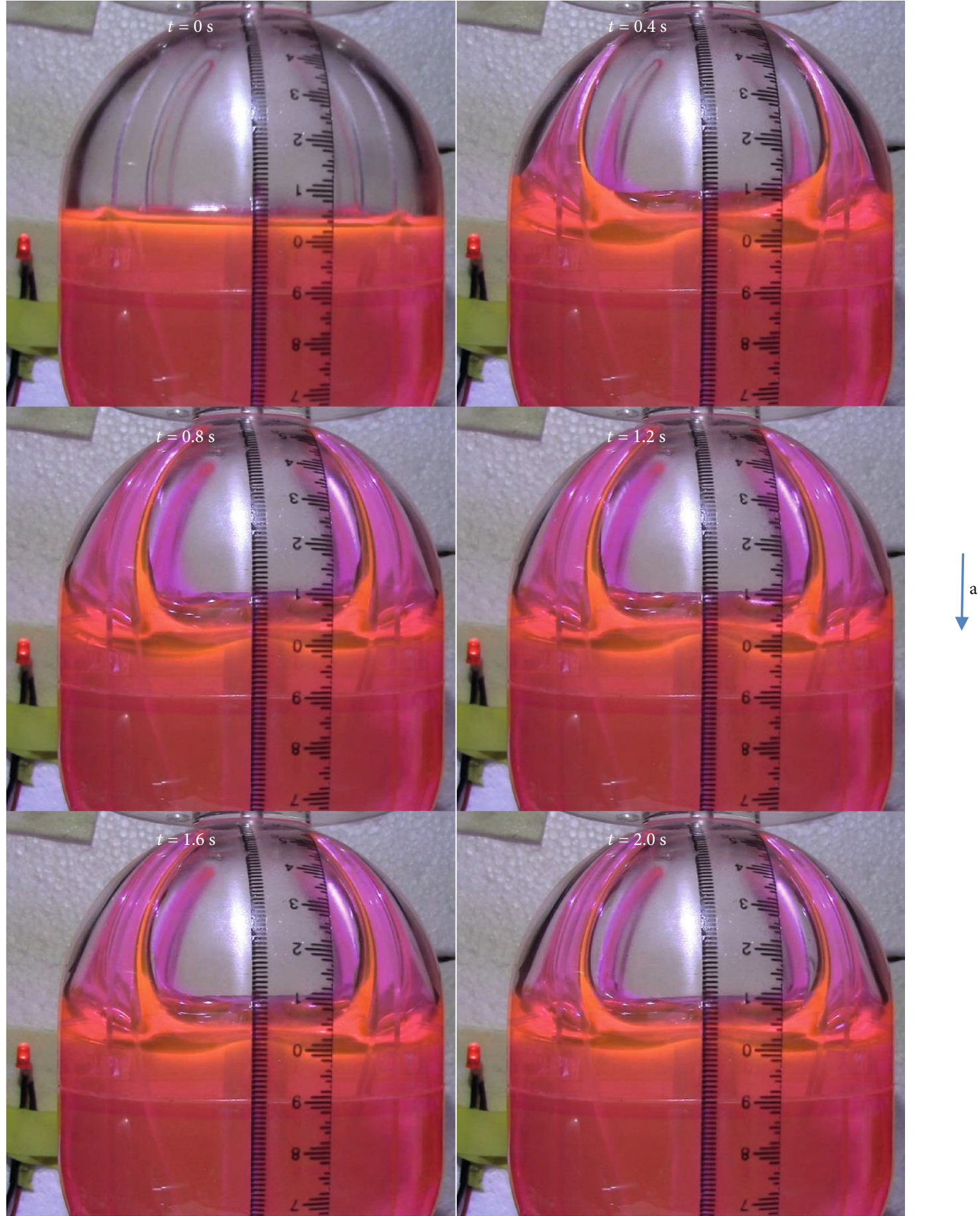

FIGURE 9: Liquid volume fraction is $60 \%$

with small curvature to the large curvature under the effect of pressure difference until the potential energy attains minimum. It is observed that the liquid climbs up rapidly along the inner and outer vane guide plates but the outer vane liquid climbs faster. After the liquid reaches the top of the blade, the liquid forms a stable gas-liquid interface.

Figure 11 shows the climbing height during the drop test. $H$ is the climbing height, and $L_{\mathrm{s}}$ is the distance from the gasliquid interface from the bottom tip of the tank to its top.
Figure 12 shows the change of flow velocity along the vane inside the tank during the drop test. The liquid climbing height along the vane under microgravity increases as the volume fraction of liquid reduces. The liquid velocity flows of different liquid volume fractions along the vane in the tank are different at the beginning $(t<0.8 \mathrm{~s})$. The liquid relocation time is $0.8 \mathrm{~s}$ when the liquid volume fraction is larger than $25 \%$. The relocation time is prolonged when the liquid volume fraction is less than $25 \%$. With the decrease of the liquid 


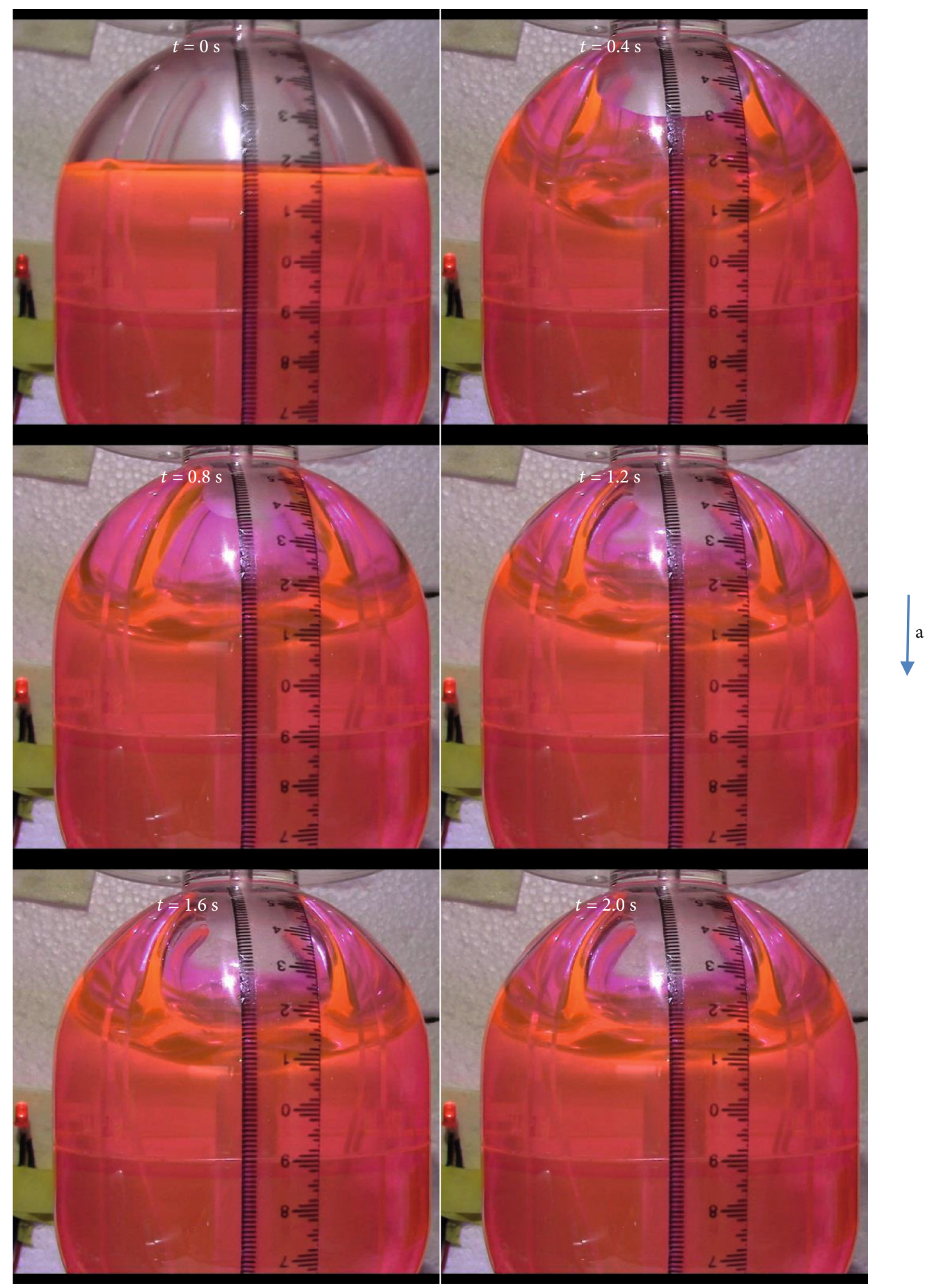

FIGURE 10: Liquid volume fraction is $75 \%$

volume in the tank, the liquid in the tank will distribute along the space between the vane and the tank. The liquid climbing height increases, and the relocation time is prolonged as the liquid volume fraction reduces. The flow velocity is approximately $0.084 \mathrm{~m} / \mathrm{s}$ when the volume fractions are $25 \%$ and $40 \%$ and approximately $0.06 \mathrm{~m} / \mathrm{s}$ when the volume fractions are $60 \%$ and $75 \%$. When the volume fraction is set to $40 \%$, the top part of the small vanes does not get covered by liquid. The liquid is affected by both large vanes and small vanes during the climbing process, while only large vanes have an effect on the liquid when the volume fractions are $60 \%$. So, the liquid at the beginning when the volume fraction is set to $40 \%$ has a faster rate compared to the case with a fraction of $60 \%$. When the volume fraction is set to $75 \%$, the liquidgas interface is in the upper hemisphere of the tank. The surface diameter of liquid-gas is smaller than the cylinder part. Smaller radius of curvature results in faster climbing rate of liquid with a fraction of $75 \%$.

At the beginning of the test, the fluid in the tank is initialized by acceleration on the Earth's surface. The potential 


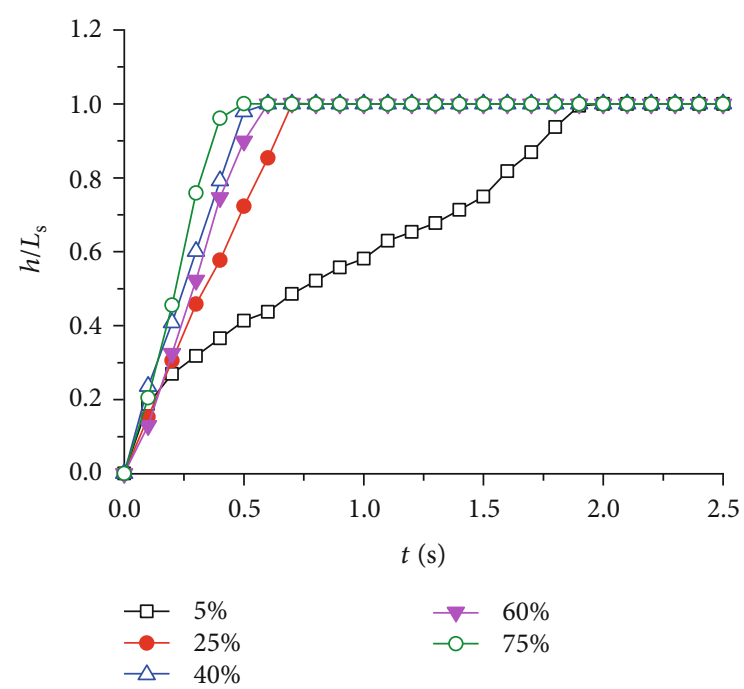

FIGURE 11: Climbing height of different volume fractions

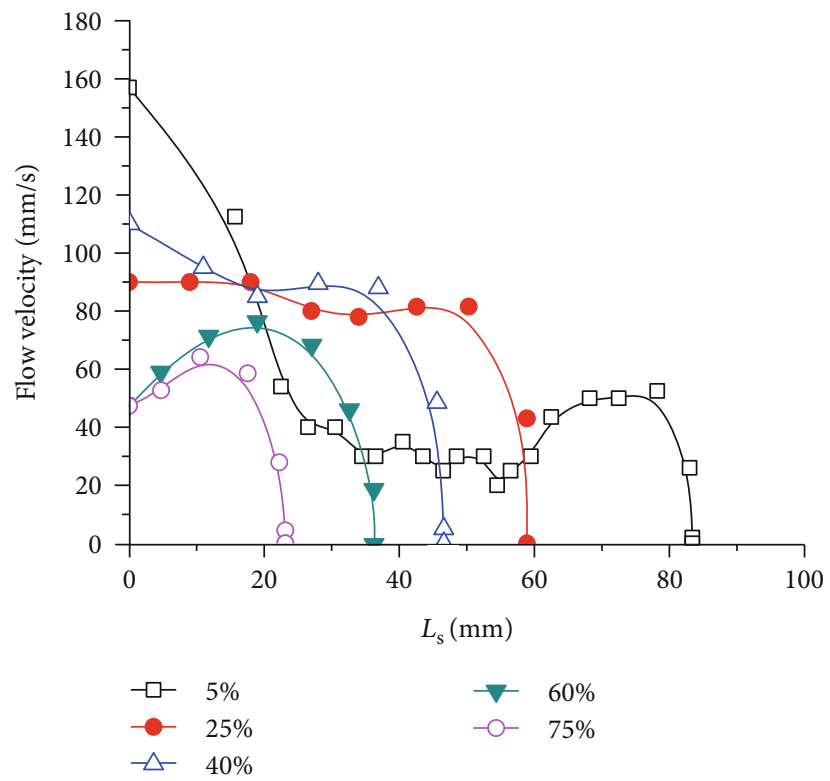

Figure 12: Flow velocity of different volume fractions

energy of liquid inside the tank is formed by the acceleration on the Earth's surface. In the drop tower test, the acceleration on the Earth's surface is changed into microgravity. The potential energy of the liquid is released. Potential energy exhibits a relationship with liquid volume. Potential energy of the liquid is small with less fluid volume. The surface tension force of the PMD has a large proportion compared to other forces. The resistance caused by the surface tension force is sufficiently larger which drives the flow velocity to decrease rapidly at the beginning when the volume fraction is $5 \%$. Hence, the fluid will spend more time reaching to steady flow. At approximate $1.2 \mathrm{~s}$, when the volume fraction is $5 \%$, the liquid flows from the cylindrical part to the top hemispherical part of the tank. The resistance caused by the surface tension force increases instantaneously due to the geometry change. Hence, the flow velocity decreases at this location.

The uncertainty of the scale is $0.1 \mathrm{~mm}$, and minimum $L_{\mathrm{s}}$ is $23 \mathrm{~mm}$ while the maximum uncertainty in measurements for $h / L_{\mathrm{s}}$ is $0.4 \%$.

According to the similarity criterion, the Bond number $\left(B_{0}\right)$ and Weber number $\left(W_{\mathrm{e}}\right)$ are used for the experiment.

The Bond number is a dimensionless quantity determined by the influence of the surface tension, which is shown as follows:

$$
\left(\frac{\rho a L^{2}}{\sigma}\right)_{m}=\left(\frac{\rho a L^{2}}{\sigma}\right)_{p}=B_{0}
$$

The Weber number is the ratio of the inertia force to the surface tension force, which is shown as follows:

$$
\left(\frac{\rho L v^{2}}{\sigma}\right)_{m}=\left(\frac{\rho L v^{2}}{\sigma}\right)_{p}=W_{e},
$$

where $\rho$ is the density of the fluid, $a$ is the gravity, $L$ is the length of the geometry, $\sigma$ is the surface tension coefficient, $v$ is the velocity flow, $m$ is the scaled model, and $p$ is the prototype.

The flow in the same Bond number and the Weber number has a relationship with time $t$ as follows:

$$
\begin{gathered}
W_{e}=\frac{\rho L^{3}}{\sigma t^{2}}, \\
\beta=\frac{\sigma}{\rho} .
\end{gathered}
$$

Then, the true time in the prototype of the tank can be calculated by the result of the scaled model as

$$
t_{p}=\sqrt{\frac{\rho_{P} L_{p}^{3}}{W_{e} \sigma_{p}}}=t_{m}\left(\frac{\beta_{m}}{\beta_{p}}\right)^{1 / 2}\left(\frac{L_{P}}{L_{m}}\right)^{3 / 2} .
$$

For example, a propellant tank is 4 times larger than the size of the above experimental model. The tank is filled by the propellant with a volume fraction of $75 \%$, and the density is $1008 \mathrm{~kg} / \mathrm{m}^{3}$. The surface tension coefficient of the propellant is $69.8 \mathrm{dyn} / \mathrm{cm}$. The relocation time can be calculated by equation (5). The relocation time $t_{\mathrm{m}}$ for the drop tower test is $0.5 \mathrm{~s}$.

$$
\begin{aligned}
t_{p} & =t_{m}\left(\frac{\beta_{m}}{\beta_{p}}\right)^{1 / 2}\left(\frac{L_{P}}{L_{m}}\right)^{3 / 2} \\
& =0.5 \times\left(\frac{21.3 \times 1008}{69.8 \times 789}\right)^{1 / 2} \times\left(\frac{4}{1}\right)^{3 / 2} \approx 2.5 \mathrm{~s} .
\end{aligned}
$$

So, the relocation time for the 4 times larger size tank is $2.5 \mathrm{~s}$. 


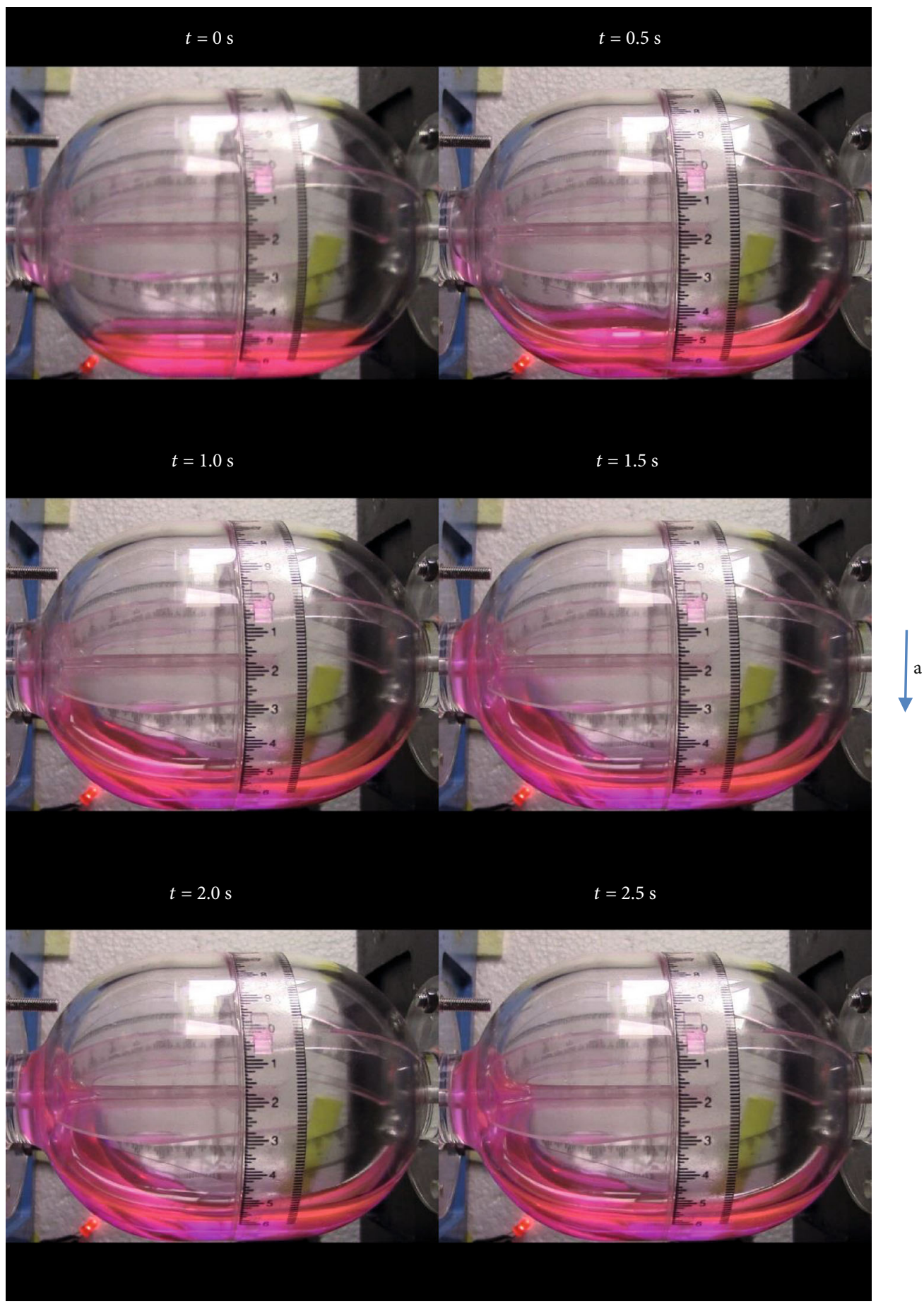

FIGURE 13: Liquid volume fraction is $5 \%$

4.2. Drop Tower Test in the Lateral Direction. Figure 13 shows the gas-liquid distribution where the liquid volume fraction is $5 \%$ in lateral gravity. After entering the microgravity environment, the liquid in the tank flows along the vane of the tank. The liquid on the side close to the gas inlet of the tank flows to the top of the vane and ceases to flow. The liquid on the left side close to the liquid outlet flows upwards, and the outlets are completely filled by liquid. Most of the liquid is collected at the outlet of the tank to meet the working needs of the tank. Figure 14 shows the gas-liquid distribution where the liquid volume fraction is $60 \%$ in lateral gravity. At this liquid volume fraction, the bubble inside the tank will gradually move to the middle close to the gas inlet.

\section{Conclusions}

A new vane-type propellant tank was experimentally studied by the drop tower test. The liquid climbing height along the vane under microgravity increases as the volume fraction of liquid reduces. The liquid relocation time is shorter than 


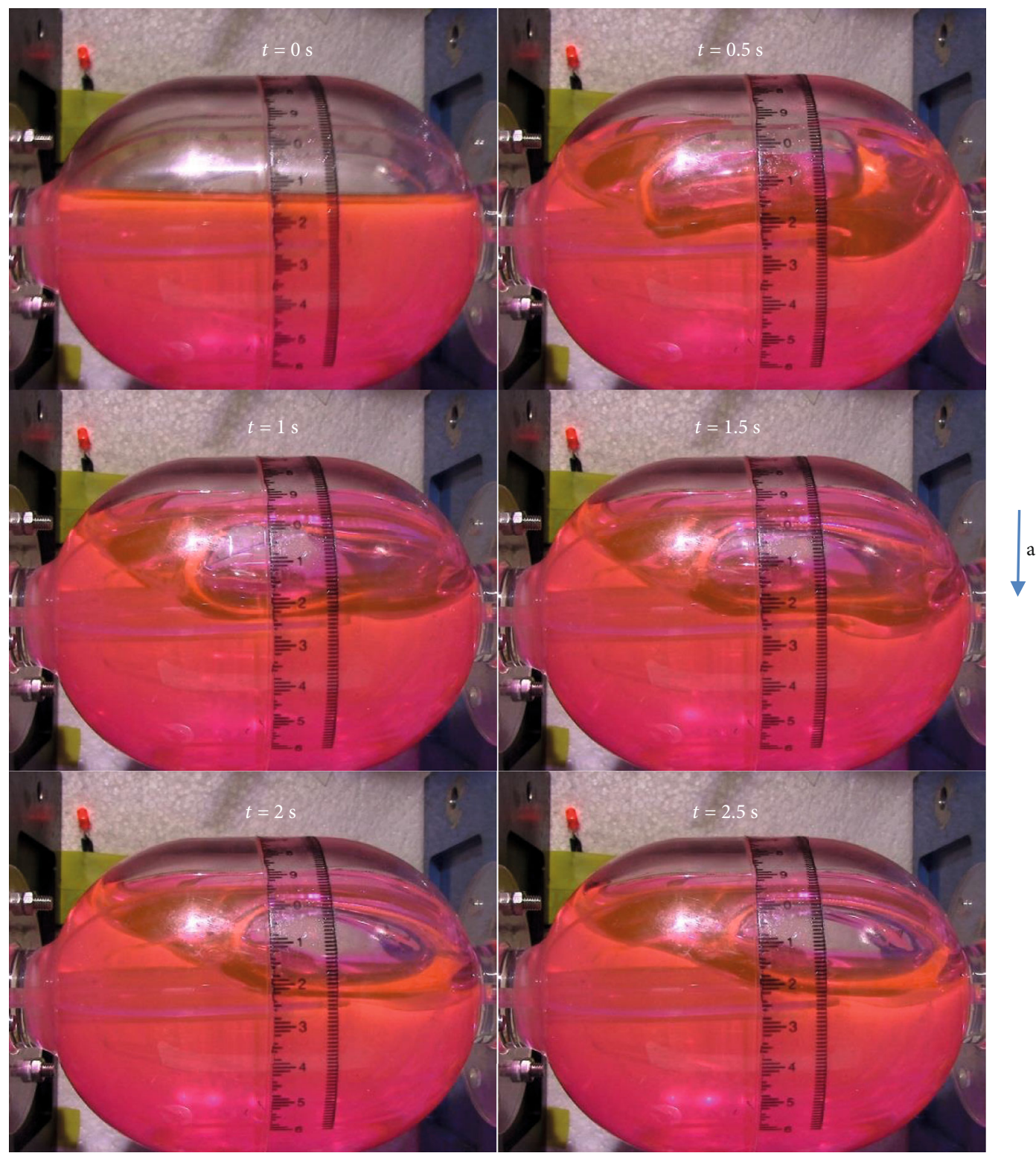

FIgURE 14: Liquid volume fraction is $60 \%$

$0.8 \mathrm{~s}$ when the liquid volume fraction is larger than $25 \%$. The liquid relocation time is prolonged to $2 \mathrm{~s}$ when the liquid volume fraction is $5 \%$. The liquid climbing height increases, and the relocation time is prolonged as the liquid volume fraction reduces. Most of the liquid is collected at the outlet of the tank to meet the requirements of the thruster. The design of a refillable reservoir should ensure that the liquid can be smoothly discharged at the end. This experiment proves that a vane-type propellant tank can be used in space with this gravity level to provide a gas-free propellant for thrusters. This kind of vane transports liquid through the rectangular area between the vane and the wall. From the result of the test, a specific law has been found. The liquid relocation time is prolonged when the liquid volume fraction is less than $25 \%$. The climbing velocity of the liquid is half reduction when the liquid volume fraction is small. It shows that the maneuverability of the satellite decreases at the end of its life.
The above results are applicable to all propellant tanks with vertical vanes. A vertical vane can make sure the liquid is transported with a maximum speed of $100 \mathrm{~mm} / \mathrm{s}$ when the liquid volume fraction is more than $25 \%$. The time for the liquid transferred from the top of the tank to the liquid outlet can be obtained. These results are very important for the control of a satellite during the whole life. The relocation time provides a reference for the maneuverability of a satellite and the altitude angle control of a satellite. The result of this experiment also illustrates that this tank can be refueled in space.

\section{Nomenclature}

$B_{0}$ : Bond number

$W_{e}$ : Weber number

$H$ : Climbing height 
$L: \quad$ Length of the model

$L_{\mathrm{s}}$ : The distance from the gas-liquid interface at the beginning to the top point of the tank

$g$ : Acceleration on the Earth's surface

a: Acceleration

$\rho: \quad$ Density of the fluid

$\sigma: \quad$ Kinematic viscosity coefficient

$m$ : Model tank

p: $\quad$ Prototype tank

v: Flow velocity.

\section{Data Availability}

The figure data used to support the findings of this study are included within the article. The video data for the experimental test used to support the findings of this study are available from the corresponding author upon request.

\section{Conflicts of Interest}

The authors declare that they have no conflicts of interest.

\section{Authors' Contributions}

Liu Jintao and Li Yong contributed equally to this work and should be considered co-first authors.

\section{Acknowledgments}

The authors would like to thank project 51776017 supported by the National Natural Science Foundation of China.

\section{References}

[1] Q. Hu, Y. Li, H. L. Pan, J. T. Liu, and B. T. Zhuang, "Numerical analysis and experiment research on fluid orbital performance of vane type propellant management device," IOP Conference Series: Materials Science and Engineering, vol. 72, no. 4, article 042042, 2015.

[2] L. Chen and J. T. Liu, "Numerical simulation of fluid flow in the vane type tank on orbital refuelling process," IOP Conference Series: Earth and Environmental Science, vol. 163, article 012085, 2018.

[3] Q. Hu and Y. Li, "Numerical simulation and experiment verification of fluid behavior in the vane type tank with big vanes in microgravity environment," Aero Control and Application, vol. 39, pp. 58-62, 2013.

[4] S. Darr and J. Hartwig, "Optimal liquid acquisition device screen weave for a liquid hydrogen fuel depot," International Journal of Hydrogen Energy, vol. 39, no. 9, pp. 4356-4366, 2014.

[5] P. Behruzi, C. Dodd, and G. Netter, "Future propellant management device concepts for restartable cryogenic upper stages," in 43rd AIAA/ASME/SAE/ASEE Joint Propulsion Conference \& Exhibit, Cincinnati, OH, USA, July 2007.

[6] J. R. Tegart, "A vane type propellant management device," in 33rd Joint Propulsion Conference and Exhibit, Seattle, WA, USA, July 1997.

[7] J. Benton, I. Ballinger, D. Jaekle, and M. Olson, "Design and manufacture of a propellant tank assembly," in 43rd AIAA/AS-
ME/SAE/ASEE Joint Propulsion Conference \& Exhibit, Cincinnati, OH, USA, July 2007.

[8] P. S. Griffin, I. A. Ballinger, D. E. Jaekle, and A. C. Jackson, "Design and manufacture of a lightweight fuel tank assembly," in 39th AIAA/ASME/SAE/ASEE Joint Propulsion Conference and Exhibit, Huntsville, Alabama, USA, July 2003.

[9] J. W. Hartwig, Liquid acquisition devices for advanced in-space cryogenic propulsion systems, [Ph.D. thesis], Case Western Reserve Univ., Cleveland, OH, 2014.

[10] M. Debreceni, W. Lay, T. Kuo, and D. Jaekle Jr., "Design and development of a communications satellite propellant tank," in 32nd Joint Propulsion Conference and Exhibit, Buena Vista, FL, USA, July 1996.

[11] M. J. Debreceni, W. D. Lay, and D. J. Jaekle, "Design and development of a PMD-type bipropellant tank," in 34th AIAA/ASME/SAE/ASEE Joint Propulsion Conference and Exhibit, Cleveland, OH, USA, July 1998.

[12] G. Netter, U. Renner, and M. Dreyer, "Design and verification of a standard surface tension propellant tank," in 35th Joint Propulsion Conference and Exhibit, Los Angeles, California, USA, June 1999.

[13] S. M. Dominick and J. R. Tegart, "Orbital test results of a vaned liquid acquisition device," 30th Joint Propulsion Conference and Exhibit, 1994, Indianapolis, IN, USA, 1994, 1994.

[14] S. M. Dominick, J. R. Tegart, S. L. Driscoll, J. D. Sledd, and L. J. Hastings, "Fluid acquisition and resupply experiments on space shuttle flights STS-53 and STS-57," 2011, NASA TP2011-216465.

[15] D. J. Chato and T. A. Martin, "Vented tank resupply experiment: flight test results," Journal of Spacecraft and Rockets, vol. 43, no. 5, pp. 1124-1130, 2006.

[16] J. R. Tegart, "Performance of a capillary propellant management device with hydrazine," in 15th Joint Propulsion Conference, Las Vegas, NV, USA, June 1979.

[17] Y. Chen, "The first experiment of on-orbit filling for satellite," Goes Global, vol. 31, pp. 12-12, 2016.

[18] W. Rui, Numerical Simulation and Experimental Research of Orbital Liquid Transport and Interface Behavior in Vane Tank, [Ph.D. thesis], Northeastern University, 2014.

[19] D. A. Bolleddula, Y. Chen, B. Semerjian, N. Tavan, and M. M. Weislogel, "Compound capillary flows in complex containers: drop tower test results," Microgravity Science \& Technology, vol. 22, no. 4, pp. 475-485, 2010.

[20] J. H. Li, X. Q. Chen, and Y. Y. Huang, "Capillary flow in the vane-type surface tension tank: drop tower test results," Applied Mechanics \& Materials, vol. 224, pp. 325-328, 2012.

[21] B. Zhuang, Y. Li, H. Pan, and Q. Hu, "Experimental investigation on fluid-storage characteristic of propellant refillable reservoir in microgravity environment," Aerospace Control \& Application, vol. 2014, no. 1, pp. 27-30, 2014.

[22] Q. Kang, L. Duan, and W. Rui, "Microgravity experiment study on the vane type surface tension tank," in 40th COSPAR Scientific Assembly, Moscow, Russia, August 2014.

[23] J. T. Liu, Y. Li, W. Li, L. Chen, and C. W. Guo, "Experimental study on liquid distribution in a vane type propellant tank," Journal of Physics: Conference Series, vol. 1314, article 012097, 2019. 